\title{
Projeto Englishtalks: Uma proposta de ensino e aprendizagem da Língua Inglesa mediada pelo Google Meet e portal even3 em tempos de pandemia
}

\author{
Englishtalks project: An English language teaching and learning proposal mediated by Google Meet \\ and even3 portal in times of pandemic \\ Proyecto Englishtalks: Una propuesta de enseñanza y aprendizaje del Inglés mediada por el portal \\ Google Meet y Even3 en tiempos de pandemia
}

Recebido: 13/05/2021 | Revisado: 20/05/2021 | Aceito: 06/06/2021 | Publicado: 17/06/2021

\author{
Joniery Rubim de Souza \\ ORCID: https://orcid.org/0000-0002-0293-2886 \\ Instituto Federal de Educação, Ciência e Tecnologia do Maranhão, Brasil \\ E-mail: joniery@ifma.edu.br \\ Tiago da Costa Barros Macedo \\ ORCID: https://orcid.org/0000-0003-4399-6269 \\ Instituto Federal de Educação, Ciência e Tecnologia do Maranhão, Brasil \\ E-mail: tiago.macedo@ifma.edu.br \\ Heloisa Guimarães Coelho \\ ORCID: https://orcid.org/0000-0002-9593-4070 \\ Instituto Federal de Educação, Ciência e Tecnologia do Maranhão, Brasil \\ E-mail: heloisaguimaraes@acad.ifma.edu.br
}

\section{Resumo}

Este artigo objetiva apresentar as ações do projeto de ensino e aprendizagem de língua inglesa chamado Englishtalks, idealizado durante o período de pandemia quando as aulas presenciais das escolas da rede pública e privada foram suspensas. O projeto consiste na realização de webinários, através da plataforma Google Meet, que têm como intuito contribuir para o desenvolvimento das habilidades linguísticas e comunicativas em língua inglesa dos participantes, a partir de orientações didáticas acerca do processo de ensino e aprendizagem e do incentivo à prática constante desta língua, por meio de dicas de como melhorar a fluência e a precisão gramatical no uso da língua alvo e do debate sobre a importância do conhecimento funcional da gramática para fins de comunicação.

Palavras-chave: Projeto Englishtalks; Abordagem comunicativa; Língua inglesa; Interação social e virtual; Teoria sociocultural.

\begin{abstract}
Understanding the different concepts of learning, such as the relationship between teaching and learning, is of utmost importance for education since learning is discussed by different educational theorists. That said, the teaching and learning process is related to the interaction between teachers and students in the educational context, and during this process situations may emerge that can affect teaching as well as learning. Thus, this research aims to identify the elements that may interfere in the teaching and learning process, presenting the internal and external factors that contribute to such interference. The research is classified as basic in nature, with a quanti-qualitative methodological approach, and its objectives are bibliographic and exploratory. A survey was carried out in the CAPES and Google Academic databases, aiming to subsidize the following questions: which factors may interfere in the teaching and learning process? What are the influences of these factors in the school space? At the end of the research, it was possible to identify that some of the factors that cause damage to learning may be related to emotional, social, and family issues.
\end{abstract}

Keywords: Englishtalks project; Communicative approach; English language; Social and virtual interaction; Sociocultural Theory.

\section{Resumen}

Este artículo pretende presentar las acciones del proyecto de enseñanza y aprendizaje de la lengua inglesa denominado Englishtalks, idealizado durante el periodo de pandemia en el que se suspendieron las clases presenciales de las escuelas públicas y privadas. El proyecto consiste en la realización de webinars, a través de la plataforma Google Meet, que pretenden contribuir al desarrollo de las competencias lingüísticas y comunicativas en lengua inglesa de los participantes, desde la orientación didáctica sobre el proceso de enseñanza-aprendizaje y el fomento de la práctica constante de esta lengua adicional, pasando por consejos sobre cómo mejorar la fluidez y la precisión gramatical en el uso de la lengua en cuestión y el debate sobre la importancia del conocimiento funcional de la gramática para la comunicación.

Palabras clave: El proyecto Englishtalks; Enfoque comunicativo; Lengua inglesa; Interacción social y virtual; Teoría sociocultural. 


\section{Introdução}

Neste artigo pretendemos apresentar uma proposta de ensino e aprendizagem de Língua Inglesa chamada Englishtalks, a qual surgiu após a suspensão das aulas tanto na instituição em que trabalhamos, o Instituto Federal do Maranhão (doravante Ifma), quanto nas demais instituições de ensino em todo o país da rede pública e privada por causa pandemia da Covid-19. Entretanto, com base na Portaria ${ }^{\circ} 1202$ do Ifma, de 18 de março de 2020, documento elaborado pelo Comitê de Crise para o Enfrentamento ao Coronavírus (COVID-19) desta instituição, baseado em outros documentos como declaração oficial de pandemia pela Organização Mundial da Saúde (OMS), portarias e instruções normativas dos Ministérios da Saúde e Educação, as atividades de pesquisa, extensão, assistência estudantil e administrativas poderiam ser mantidas desde que fossem consideradas os protocolos de saúde e que a realização destas atividades ocorresse de maneira remota (Ifma, 2020).

Em face disso, a exemplos de tantos outros educadores que tiveram que se "reinventar" às pressas diante deste cenário desafiador, fizemos o seguinte questionamento: como poderíamos criar alguma estratégia de ensino que pudesse estimular o ensino e aprendizagem da língua inglesa tanto para os nossos alunos quanto para outras pessoas interessadas em tempos de pandemia? Foi a partir deste questionamento que surgiu a ideia de criarmos o projeto Englishtalks, uma série de webinários com dicas e orientações didáticas no ensino e aprendizagem de língua inglesa.

Desta forma, para melhor entendimento deste projeto de ensino, mas que também trabalhou a extensão e a pesquisa, estruturamos o artigo da seguinte maneira. Primeiramente, apresentaremos o projeto Englishtalks como uma proposta de webinários para o ensino remoto ancorado na teoria Sociocultural de aprendizagem e na Abordagem Comunicativa de ensino de Língua Inglesa. Logo depois, apresentaremos os procedimentos metodológicos deste projeto e os feedbacks que recebemos dos participantes dos webinários. Por fim, faremos as considerações finais do artigo.

\section{Referencial Teórico}

Como falamos anteriormente, compreendemos que o projeto Englishtalks é voltado para uma perspectiva de ensino remoto. Concordamos com Coscarelli (2020), quando esta autora explica que o contexto da pandemia forçou as escolas, sobretudo as particulares, a se prepararem para o trabalho com o ensino remoto em contraposição à educação à distância (EAD), que requereria maior planejamento e preparação prévia. A autora explica:

Chamamos ensino remoto e não educação a distância (EaD), porque é uma ação emergencial, são cursos presenciais, que, devido aos impedimentos impostos pela fácil disseminação do coronavírus, impedem os estabelecimentos de ensino de manterem suas atividades presenciais. O ensino remoto precisou ser feito sem planejamento prévio, sem um ambiente virtual de aprendizagem escolhido com cautela, sem que os professores tivessem tempo de se preparar, de produzir e selecionar materiais e estratégias de ensino adequadas para atividades online (Coscarelli, 2020).

No caso do referido projeto, ele não contaria como hora/aula para cômputo de nossas cargas horárias haja vista a suspensão das aulas presenciais e a impossibilidade de ensino remoto pelo Ifma na época em que a Portaria $\mathrm{n}^{\mathrm{o}} 1202$ foi publicada. Ademais, ainda que sejamos professores na mesma instituição, trabalhamos em campi diferentes, isto é, nos campi de Caxias, localizado ao leste do Maranhão a uma distância de aproximadamente 362 km da capital São Luís, e São Raimundo das Mangabeiras, localizado no sul do Maranhão a uma distância de aproximadamente $725 \mathrm{~km}$ da capital São Luís. Entretanto, o propósito principal do projeto Englishtalks era contribuir para o desenvolvimento das habilidades linguísticas e comunicativas em Língua Inglesa dos participantes por meio de uma programação periódica de webinários, em que seriam apresentadas orientações didáticas no processo de ensino e aprendizagem desta língua adicional.

Além do aspecto voltado ao ensino deste projeto, passamos a divulgar os webinários não apenas para o público interno de alunos e servidores do Ifma, mas também para estudantes de outras instituições de ensino bem como para a comunidade em geral, 
e tivemos a participação de várias pessoas de diferentes partes do Maranhão que não estão vinculadas diretamente ao Ifma, o que reforça também o seu caráter de projeto de extensão. Por fim, também acrescentamos a importância da pesquisa na realização dos webinários, devido à preparação do material de apresentação em que procurávamos estar bem embasados em pesquisas científicas, mídias sociais e sites didáticos, aplicativos de celular e outros recursos alternativos ou inovadores para dar subsídio aos participantes a fim de continuarem desenvolvendo seu conhecimento em língua inglesa.

No que diz respeito às teorias de aprendizagem e de língua que têm dado sustentação ao projeto Englishtalks, decidimos adotar os princípios da Teoria Sociocultural de Aprendizagem (Vygotsky, 1978), também conhecida como Sociointeracionismo Discursivo, e a Abordagem Comunicativa no Ensino de Línguas (Wilkins, 1994). Com relação à teoria de aprendizagem vigotskiana abordaremos brevemente os conceitos de mediação, zona de desenvolvimento proximal (ZDP) e andaime scaffolding (Wood, Bruner \& Ross, 1976) e como tais conceitos foram aplicados na execução deste projeto. Já no tocante à Abordagem Comunicativa do ensino de Língua Inglesa, trabalharemos o conceito de desenvolvimento de competência comunicativa assim como o aprimoramento das quatro habilidades linguísticas dentro de um contexto de interdependência entre língua e comunicação (Richard \& Rodgers, 1994).

Conforme Paiva (2014), os estudos da teoria sociocultural surgiram com o psicólogo russo Vygotsky e desde então têm influenciado vários pesquisadores que buscaram aplicá-los na aquisição de segunda língua. A princípio, os estudos de Vygotsky estiveram associados a temas como a mediação simbólica, o pensamento e a linguagem, o desenvolvimento e aprendizado, porém conceitos como mediação, zona de desenvolvimento proximal (ou zona próxima ao desenvolvimento) e andaime estão intimamente associados ao processo de aquisição de segunda língua. Segundo Paiva (2014) as principais teses de Vygotsky são: i) não se pode separar o desenvolvimento da linguagem do contexto histórico e social; ii) os humanos "pensam através da criação e do uso de ferramentas mediadoras" (Swain, Kinnear \& Steinman, 2011); iii) a linguagem tem papel importante no desenvolvimento mental, sendo ela a principal ferramenta de mediação.

No que diz respeito à mediação, conforme a teoria sociocultural, defende-se que a aprendizagem é um processo mediado, organizado a partir dos artefatos culturais, atividades e conceitos. Paiva (2014) esclarece que tais artefatos culturais podem ser tanto ferramentas físicas tais como o livro, o martelo ou uma faca quanto ferramentas simbólicas como o sistema numérico e a própria linguagem. Entretanto, para que a mediação aconteça efetivamente, é necessário que o aprendiz interaja de maneira ativa com o meio, com os seus pares e consigo mesmo dentro de um contexto sócio-histórico.

Outro conceito importante de Vygotsky na aquisição de segunda língua é a zona de desenvolvimento proximal (ZPD) e que está intimamente associado à ideia de interação e mediação entre um aprendiz e um especialista e o aprendiz e os seus pares. Este conceito é definido e aplicado por Vygotsky da seguinte forma:

A distância entre o nível de desenvolvimento real, determinado pela solução do problema de forma individual e o nível de desenvolvimento potencial, determinado pela solução de problema sob a orientação de um adulto ou em colaboração com colegas mais capazes (...) Assim, a zona próxima ao desenvolvimento nos permite delinear o futuro imediato da criança e seu estado dinâmico de desenvolvimento, identificando não apenas o que já foi alcançado, mas também o que está em processo de amadurecimento (Vygotsky, 1978, \& Paiva, 2014).

Com base nesta definição, a aquisição de segunda língua nesta teoria pode ser exemplificada no contexto de sala de aula onde o professor de segunda língua não é mais o transmissor do conhecimento, mas um mediador, auxiliando os alunos no processo de amadurecimento e desenvolvimento da segunda língua, o que muitas vezes não seria possível eles atingirem este nível de desenvolvimento mental por si mesmos.

Além disso, o professor ou o especialista desempenha também um papel de tutor ao auxiliar alguém menos adulto ou menos especialista (o aluno) no desenvolvimento de seu aprendizado. Dentro deste mesmo conceito de ZDP, podemos também 
apresentar a metáfora de andaime, proposta por Wood, Bruner e Ross (1976), definida por estes autores como "o processo que habilita uma criança ou um aprendiz a resolver um problema, executar uma tarefa ou alcançar um objetivo que estaria além de seus esforços se não houvesse uma assistência” (Wood, Bruner \& Ross, 1976).

Entendemos que os conceitos de mediação, ZDP e andaime da Teoria Sociocultural de Aprendizagem se relacionam a proposta de ensino e aprendizagem do projeto Englishtalks pelos seguintes motivos:

1) Como idealizadores e coordenadores do projeto, procuramos nos apresentar como mediadores do conhecimento, referente aos assuntos de língua inglesa abordados, propondo dicas e dando orientações didáticas para o desenvolvimento da autonomia dos participantes;

2) Utilizamos duas ferramentas digitais como mecanismos de mediação de nossos webinários: a plataforma Google Meet ${ }^{l}$, para criação de salas virtuais e apresentação de todos os webinários em formato síncrono, e o Portal Even $3^{2}$, para fins de divulgação do projeto, inscrição e credenciamento dos participantes e envio de notificações aos participantes por e-mail tais como os links das salas virtuais no Google Meet e certificados do evento;

3) Trabalhamos com um público bem heterogêneo em nossos webinários, desde alunos de ensino médio até professores de língua inglesa e servidores do Ifma, de maneira que procuramos seguir a proposta da ZDP, apresentando tanto os conhecimentos básicos quanto os de caráter mais avançado sobre os temas escolhidos bem como sugestões sobre como aprofundar ainda mais os conhecimentos de língua inglesa sobre este tema;

4) A metáfora do andaime de Wood, Bruner \& Ross (1976) nos parece ser adequada para ilustrar o trabalho que desenvolvemos no projeto Englishtalks, pois buscamos prover assistência e tutoria aos participantes dos webinários a fim de que eles tivessem subsídios e recursos para a formação continuada na aprendizagem da língua inglesa.

Como falamos anteriormente, além da Teoria Sociocultural de Aprendizagem, buscamos aporte teórico também na Abordagem Comunicativa no Ensino de Língua Inglesa. Em princípio, entendemos o conceito de abordagem de acordo com a perspectiva de Richards \& Rodgers (1994), isto é, “a abordagem refere-se às teorias de língua e da aprendizagem de língua que servem como fonte de práticas e princípios no ensino de línguas”. Deste modo, a abordagem seria compreendida como o embasamento teórico para um método de ensino, entendido neste contexto como o "conjunto de princípios teóricos, princípios organizacionais e ações práticas que norteiam a estruturação de um curso, o planejamento das aulas, a avaliação de aprendizagem e a escolha de materiais didáticos" (Lima, 2014).

Segundo Lima (2014), quando se fala de Abordagem Comunicativa, dificilmente pode-se atribuir a apenas um teórico a responsabilidade em desenvolver propostas metodológicas que fossem voltadas para um viés comunicativo para o ensino de línguas, mas sim a vários estudiosos. Dentre estes, destaca-se Hymes (1979) por ter cunhado o conceito de competência comunicativa, a partir de um deslocamento do conceito de competência de Chomsky³, definido por este autor como "o conhecimento que o falanteouvinte possui da sua língua” (Chomsky, 1978). Entretanto, para Hymes, para que o falante-ouvinte seja competente em sua língua, além de conhecimentos de regras gramaticais, ele também precisa da habilidade "de usar essas regras, adequando-as às situações sociais em que se encontra no momento em que usa a língua” (Lima, 2014).

Além de Hymes, outros teóricos também deram sua contribuição para a construção da Abordagem Comunicativa no ensino de Línguas. Canale e Swain (1980), por exemplo, comentam a respeito de competências importantes que os aprendizes de línguas precisam ter para adquirir a competência comunicativa, tais como as competências gramatical, sociolinguística, discursiva e

\footnotetext{
${ }^{1} \mathrm{O}$ motivo pelo qual usamos o Google Meet, dentre outras plataformas que tenham funcionalidades semelhantes, é porque o Ifma tem a assinatura do pacote Google for Education para todos seus servidores, o que inclui uma série de aplicativos e serviços desta empresa como a plataforma mencionada anteriormente, assim como o Gmail, o Google Drive, entre tantos outros.

${ }^{2}$ Endereço eletrônico do Projeto Englishtalks: https://www.even3.com.br/englishtalks/.

${ }^{3}$ Segundo Lima (2014), o propósito de Chomsky ao propor a teoria de competência e também de desempenho, o qual diz respeito ao uso efetivo da língua em situações concretas (Chomsky, 1978), o foco deste pesquisador não era tratar de questões ligadas ao ensino de línguas, mas sim "estudar os conhecimentos linguísticos estruturais do falante-ouvinte para tentar explicar como a mente do ser humano processa a linguagem” (Lima, 2014).
} 
estratégica ${ }^{4}$. Richards and Rodgers (1994), a partir de uma análise feita pelas proposições de teóricos norte-americanos e britânicos a respeito da Abordagem Comunicativa, esclarecem que o objetivo desta abordagem é "tornar a competência comunicativa o objetivo do ensino de línguas e desenvolver procedimentos para o ensino das quatro habilidades comunicativas que reconheçam a interdependência entre a língua e a comunicação". Por sua vez, Wilkins (1994) propõe que o syllabus ${ }^{5}$ da Abordagem Comunicativa deve ser de caráter nocional ou semântico, considerando as necessidades comunicativas dos aprendizes em noções semânticas e funções comunicativas.

Embora existam outros teóricos que deram contribuições significativas para a Abordagem Comunicativa, pretendemos apresentar os principais aspectos teóricos gerais desta abordagem e como eles estão relacionados com o projeto Englishtalks. A seguir, apresentamos um quadro com os aspectos teóricos da Abordagem Comunicativa conforme elencados por Lima (2014) e como eles estão contextualizados com o projeto Englishtalks:

Quadro 1: Contextualização entre aspectos teóricos da Abordagem Comunicativa com o projeto Englishtalks.

\begin{tabular}{|c|c|}
\hline $\begin{array}{c}\text { Aspectos teóricos da Abordagem Comunicativa } \\
\text { conforme Lima (2014) }\end{array}$ & $\begin{array}{c}\text { Relação entre estes aspectos com o Projeto } \\
\text { Englishtalks }\end{array}$ \\
\hline A língua é concebida como interação social & $\begin{array}{l}\text { Durante os webinários, além da apresentação dos } \\
\text { professores coordenadores, havia uma bolsista } \\
\text { moderadora que acompanhava as conversas e comentário } \\
\text { no chat da sala virtual e selecionava as perguntas ou } \\
\text { comentários feitos pelos participantes na parte final de } \\
\text { cada webinário a fim de que os professores respondessem }\end{array}$ \\
\hline $\begin{array}{l}\text { As estruturas gramaticais não são o foco primordial no } \\
\text { ensino comunicativo de línguas, mas também são alvo da } \\
\text { atenção do professor a fim de ensinar seus alunos a usar } \\
\text { tais estruturas adequadamente }\end{array}$ & $\begin{array}{l}\text { Nos dois webinários em que trabalhamos tópicos } \\
\text { gramaticais, apresentamos alternativas para se aprender a } \\
\text { gramática de maneira mais contextualizada com o uso da } \\
\text { língua. }\end{array}$ \\
\hline $\begin{array}{l}\text { O aprendiz é visto como um ser capaz de construir seus } \\
\text { conhecimentos e de negociar sentidos nas interações } \\
\text { sociais }\end{array}$ & $\begin{array}{l}\text { Nos webinários em que tratamos sobre o desenvolvimento } \\
\text { das habilidades comunicativas, buscamos enfatizar a } \\
\text { importância da negociação de significados, bem como } \\
\text { outras estratégias de compensação para possíveis entraves } \\
\text { comunicativos }\end{array}$ \\
\hline $\begin{array}{l}\text { O professor é um facilitador da aprendizagem e não um } \\
\text { modelo a ser imitado }\end{array}$ & $\begin{array}{l}\text { Como defensores do inglês como língua franca, } \\
\text { procuramos apresentar dicas, explicações e outros } \\
\text { recursos como aplicativos de celular, livros, sites da } \\
\text { internet e mídias sociais para que os participantes de } \\
\text { nossos webinários continuem aprendendo de maneira } \\
\text { autônoma }\end{array}$ \\
\hline $\begin{array}{l}\text { Os erros dos alunos são tolerados porque são vistos como } \\
\text { parte integrante e natural do processo de aprendizagem }\end{array}$ & $\begin{array}{l}\text { Em dois dos webinários realizados neste projeto, } \\
\text { abordamos maneiras alternativas de se aprender gramática } \\
\text { em língua inglesa e sugerimos usos mais correntes de } \\
\text { expressões em língua inglesa do que outras construções } \\
\text { que podem ser soar equivocadas no uso da língua, mas que } \\
\text { na aprendizagem destes usos, eventuais desvios ou erros } \\
\text { podem ocorrer visando o aperfeiçoamento do aprendiz no } \\
\text { conhecimento da língua }\end{array}$ \\
\hline $\begin{array}{l}\text { O objetivo do ensino é auxiliar o aluno a desenvolver sua } \\
\text { competência comunicativa }\end{array}$ & $\begin{array}{l}\text { Em todos os webinários realizados neste projeto, } \\
\text { procuramos enfatizar o desenvolvimento da competência } \\
\text { comunicativa tanto para as habilidades comunicativas } \\
\text { orais e de escrita quanto no conhecimento de vocabulário } \\
\text { e uso de gramática }\end{array}$ \\
\hline
\end{tabular}

Fonte: Autores.

\footnotetext{
${ }^{4}$ Segundo Canale e Swain (1980), a competência gramatical consiste no reconhecimento das características linguísticas da língua, por parte do aprendiz, para formulação de enunciados. A competência sociolinguística deve levar o aprendiz a conhecer as regras sociais que direcionam o uso da língua bem como o contexto social onde ela é empregada. A competência discursiva diz respeito à conexão entre orações e enunciados com o intuito de formar um todo signific ativo e acontece de maneira compartilhada na relação entre falante/escritor e ouvinte/leitor e, por fim, a competência estratégia está relacionada a estratégias de enfrentamento por parte do aprendiz caso haja alguma limitação no conhecimento de alguma regra gramatical da língua (Silva, 2004).

5 "Descrição de conteúdos de um curso de instrução e a ordem em que eles serão ensinados". (Richards \& Schmidt, 2010)
} 
Depois de contextualizarmos o projeto Englishtalks tanto com os conceitos de mediação, ZDP e andaime da Teoria Sociocultural de Aprendizagem quanto com vários aspectos teóricos comuns à Abordagem Comunicativa no Ensino de Línguas, apresentaremos a seguir os procedimentos metodológicos detalhadamente bem como os resultados parciais da aplicação deste projeto, uma vez que ele ainda está em execução.

\section{Aplicação do Projeto Englishtalks e Feedbacks dos Participantes}

Este estudo se constitui de um relato de experiência exitosa, a partir da criação do projeto Englishtalks, por ocasião do surgimento da pandemia mundial da Covid-19, no ano de 2020. Os webinários foram divididos em duas temporadas: a primeira temporada ocorreu entre os meses de maio a julho 2020 e contou com quatro episódios, enquanto que a segunda começou no mês de agosto e se encerrou no mês de dezembro. Como afirmamos anteriormente, cada webinário foi realizado dentro de uma sala virtual na Plataforma Google Meet, de maneira que cada apresentação foi gravada e posteriormente postada no Youtube, com exceção do terceiro episódio da segunda temporada, o qual foi realizado em formato de live pelo Youtube. A seguir apresentamos um quadro com os títulos de cada episódio de cada temporada, data em que eles foram realizados e endereço eletrônico de acesso aos webinários ${ }^{6}$ :

Quadro 2: Webinários realizados pelos coordenadores do Projeto Englishtalks.

\begin{tabular}{|l|l|}
\hline \multicolumn{2}{|c|}{ Projeto Englishtalks } \\
\hline Season 1 (1 ${ }^{\text {a }}$ Temporada) & $\begin{array}{l}\text { Episode 1 - Keep Calm and Learn Grammar Easily, no dia 15/05 } \\
\text { (https://www.youtube.com/watch?v=fKLFMUhpQ_M); } \\
\text { Episode 2 - Getting to Know distinct reading strategies in ESP, no dia 01/06 } \\
\text { (https://www.youtube.com/watch?v=5IvlNSNaNZc); } \\
\text { Episode 3 - Faça um upgrade no seu vocabulário de inglês no dia 19/06 } \\
\text { (https://www.youtube.com/watch?v=tLqxxohfM5U); } \\
\text { Episode 4 - Construções equivocadas em língua inglesa, no dia 03/07 } \\
\text { (https://www.youtube.com/watch?v=0tRicgJOdYM) }\end{array}$ \\
\hline Season 2 (2 ${ }^{\mathrm{a}}$ Temporada) & $\begin{array}{l}\text { Episode 1 - Como destravar a conversação em inglês, no dia 28/08 } \\
\text { (https://www.youtube.com/watch?v=rvCxNMviCv4); } \\
\text { Episode 2 - Técnicas para melhorar a compreensão auditiva (listening) em } \\
\text { inglês, no dia 25/09 (https://www.youtube.com/watch?v=fqZaZqKB_u8); } \\
\text { Episode 3 - Expressões idiomáticas (idioms) em inglês que você precisa saber, } \\
\text { no dia 28/11 (https://www.youtube.com/watch?v=PJ7x6xj3IeY\&t=494s) }\end{array}$ \\
\hline
\end{tabular}

Fonte: Autores.

No primeiro webinário da primeira temporada, Keep Calm and Learn Grammar Easily (Mantenha a calma e aprenda gramática facilmente), até então realizado sem a participação de um moderador, apresentamos alternativas para o estudo e aprofundamento de tópicos gramaticais em língua inglesa como, por exemplo, leitura, descrição e análise de gêneros textuais diversos como o meme, tiras cômicas, banners, letras de música, gifs, poemas, piadas, assim como atividades gramaticais em canções usando apresentações no Microsoft Power Point, aprendizagem de tópicos gramaticais em episódios de séries, filmes e

\footnotetext{
${ }^{6}$ Com o apoio de uma das monitoras e moderadoras do projeto Englishtalks, criamos um canal do Youtube tratando especificamente sobre este projeto chamado Projeto English Talks, disponível no seguinte endereço: https://www.youtube.com/channel/UC1UMN9Nq19G6P9wDwphGGaA. Vale acrescentar que todos os links dos webinários citados no quadro acima estão vinculados a este canal.
} 
indicações de sites que forneçam estratégias para a aprendizagem da gramática da língua inglesa.

Já no segundo webinário desta mesma temporada, Getting to know distinct strategies in ESP (Conhecendo estratégias distintas em Inglês para Propósitos Específicos), apresentamos estratégias de leitura para compreensão de textos acadêmicos em língua inglesa com ênfase em estratégias cognitivas como fazer conexões, encontrar evidência textual e questionamentos assim como estratégias linguísticas tais como identificação e compreensão de sintagmas nominais, referência pronominal e marcadores discursivos. Vale ressaltar que a partir deste webinário assim como os subsequentes, tivemos o apoio de uma moderadora, a acadêmica de Ciências da Computação Heloisa Guimarães, do Ifma Campus Caxias.

O terceiro episódio da primeira temporada, Faça um upgrade no seu vocabulário de inglês, apresentamos dicas aos participantes a fim de desenvolver o conhecimento lexical deles, trabalhando com collocations (co-ocorrências ou combinações lexicais) em textos escritos, canções e filmes, assim como outros hábitos de grande importância para a aprendizagem de vocabulário como a leitura, a escrita, a prática de compreensão auditiva, jogos, utilização de sites didáticos e aplicativos úteis para o desenvolvimento lexical em língua inglesa dos participantes. Por fim, o quarto e último episódio da primeira temporada, Construções equivocadas em língua inglesa, buscamos apresentar algumas construções em língua inglesa que podem soar equivocadas pelo fato de vários aprendizes tentarem fazer equivalências da sua língua materna (no caso deste webinário, a língua portuguesa) com a língua adicional (a língua inglesa) e apresentamos vários exemplos com as construções linguísticas mais apropriadas ao contexto social em que elas são empregadas.

Quando iniciamos a segunda temporada do projeto Englishtalks, uma das inovações propostas foi o lançamento do site do projeto no portal Even3, uma ferramenta que ajudou bastante no processo de mediação deste projeto, conforme falamos anteriormente, ao contextualizarmos a teoria vigotskiana com a aplicação deste projeto de ensino e aprendizagem. Ademais, também trabalhamos com outras estratégias de divulgação do projeto como matérias veiculadas no site institucional do Ifma, bem como em outros sites e até mesmo participação em jornais televisivos de abrangência local ou regional no estado do Maranhão. No primeiro episódio desta segunda temporada, Como destravar a conversação em inglês, apresentamos dicas importantes para aperfeiçoar a produção oral (speaking) em língua inglesa, tais como a desmistificação de algumas crenças relacionadas a este assunto como a impossibilidade de aprender inglês depois da fase adulta, bem como a integração de outras habilidades comunicativas no desenvolvimento da oralidade, a importância da imersão em língua inglesa, exercício de técnicas orais como cantar em inglês ou shadowing e aplicativos de celular úteis para o desenvolvimento da oralidade.

No segundo episódio desta temporada, Técnicas para melhorar a compreensão auditiva (listening) em inglês, contamos com a colaboração de uma amiga professora de inglês, Laura Tinoco, e abordamos diferentes dicas para aprimorar a compreensão auditiva dos participantes tais como atentar para o som átono e extremamente comum do schwa /o/ em vários enunciados da língua inglesa, escolher um input compreensível e focar no contexto comunicativo em que você está acompanhando determinado diálogo ou apresentação de um texto oral. Por fim, no terceiro e último episódio da segunda temporada do projeto Englishtalks, Expressões idiomáticas (idioms) em inglês que você precisa saber, também tivemos a participação de outro amigo professor de inglês, Reginaldo Nascimento, e trabalhamos o conceito de expressões idiomáticas, em que contextos comunicativos as utilizamos, explicamos a origem de algumas destas expressões, seu teor metafórico e apresentamos vários exemplos delas. Vale ressaltar que este terceiro episódio foi o primeiro a ser transmitido via streaming pelo canal oficial do projeto Englishtalks no Youtube.

No que diz respeito aos feedbacks dos participantes dos webinários, verificamos que em cada webinário, contamos com a presença de 30 a 70 participantes nas salas virtuais do Google Meet, mais de 160 inscrições no site do evento no Portal Even3 e cerca de 100 visualizações na live feita pelo Youtube no último episódio da segunda temporada. Os participantes fizeram diversas perguntas tais como o melhor método para se aprender língua inglesa, dicas para melhorar a leitura em inglês, como pensar em inglês, aplicativos úteis para estar em contato com falantes nativos da língua inglesa, diferença de sotaques em língua inglesa, entre outras. Além disso, em um dos formulários Google enviados pela moderadora dos webinários para confecção de certificados dos 
participantes, foi destinado um espaço para críticas, sugestões e ideias para futuros webinários e vários participantes responderam. Em geral, os participantes elogiaram o projeto e sugeriram temas como sons desafiadores em língua inglesa, sugestão de bons dicionários e gramáticas e realização de uma palestra toda em inglês.

\section{Considerações Finais}

Neste artigo, buscamos apresentar o projeto Englishtalks, uma iniciativa de produção de webinários de ensino e aprendizagem de língua inglesa tendo como metodologia o ensino remoto ancorado na teoria Sociocultural de aprendizagem e na Abordagem Comunicativa no ensino de línguas e mediado pelas ferramentas Google Meet e Portal Even3. Descrevemos e analisamos cada episódio ou webinário realizado (um total de sete webinários divididos em duas temporadas), bem como fizemos a exposição de alguns feedbacks que recebemos tanto na interação virtual síncrona nas salas criadas por intermédio da plataforma Google Meet quanto por meio de um formulário Google enviado aos participantes, os quais se manifestaram com elogios e sugestões para os próximos episódios deste projeto.

\section{Referências}

Canale, M. \& Swain, M. (1980). Theoretical bases of communicative approaches to second language teaching and testing. In: Applied Linguistics, 1.

Chomsky, N. (1978). Aspectos da teoria da sintaxe. Trad.: J. A. Meireles e E. P. Raposo. Arménio Amado, [1965].

Coscarelli, C. (2020). Ensino de língua: surtos durante a pandemia. In: Ribeiro, A. E.; Vecchio, P. M. M. Tecnologias digitais e escola [recurso eletrônico]: reflexões no projeto aula aberta durante a pandemia. Parábola.

Hymes, D. H. (1979). On Communicative Competence. In: Brumfit, C. J. \& Johnson, K. The Communicative Approach to Language Teaching. Oxford: Oxford University Press.

Ifma. Portaria $n^{o}$ 1202, 18 de março de 2020. https://portal.ifma.edu.br/wp-content/uploads/2020/03/Portaria-1202-2020.pdf.

Oliveira, L. A. (2014). Métodos de ensino de inglês: teorias, práticas, ideologias. Parábola.

Paiva, V. L. M. O. (2014). Aquisição de segunda língua. Parábola.

Richards, J. \& Rodgers, T. (1994). Approaches and Methods in Language Teaching: A Description and Analysis. Cambridge: Cambridge University Press.

Richards, J., \& Schmidt, R. (2010). Syllabus. In: Longman Dictionary of Language Teaching and Applied Linguistics. (4a ed.) Pearson.

Silva, V. L. T. (2004). Competência Comunicativa em Língua Estrangeira: que conceito é esse? Soletras, Ano IV, Nº8. UERJ.

Swain, M., Kinnear, P. \& Steinman, L. (2011). Sociocultural Theory in Second Language Education: An Introduction Through Narratives. Bristol: Mulitilingual Matters.

Vygotsky, L. S. (1978). Mind in Society: The Development of Higher Psychological Processes. Cole, M. et al (orgs.). Harvard University Press.

Wilkins, D. A. (1994). Grammatical, Situational and Notional Syllabuses. In: Brumfit, C., Johnson, K. (orgs.). The Communicative Approach to Language Teaching. Oxford University Press, p. 82-90.

Wood, D., Bruner, J. S. \& Ross, G. (1976). The role of tutoring in Problem Solving. Journal of Child Psychology and Psychiatry and Allied Disciplines, 17(2), 89100 . 